\title{
Evaluation of Physiotherapy Impact on Rotator Cuff Shoulder Tendinopathy in Hypothyroid and Diabetic patients
}

\author{
Ashraf Elsayed Amer ${ }^{1}$ MD; Hany Mohamed Aly ${ }^{1, *}$ MD;Abdullah Mostafa Gaafar ${ }^{2}$ MD;
} Mohamed Abouelnaga Mohamed Belih ${ }^{2} \mathrm{MD}$

\author{
*Corresponding Author: \\ Hany Mohamed Aly \\ hanyaly79@azhar.edu.eg
}

Received for publication July 22, 2021; Accepted September 22, 2021; Published online September 22,2021.

Copyright The Authors published by Al-Azhar University, Faculty of Medicine, Cairo, Egypt. Users have the right to read, download, copy, distribute, print, search, or link to the full texts of articles under the following conditions: Creative Commons AttributionShare Alike 4.0 International Public License (CC BY-SA 4.0).

doi: 10.21608/aimj.2021.87119.1532

${ }^{1}$ Rheumatology And Rehabilitation Department,Faculty of Medicine, Al-Azhar University, Cairo, Egypt.

${ }^{2}$ Clinical Pathology Department Faculty of Medicine, Al-Azhar University, Cairo, Egypt.

${ }^{3}$ Radiology Department , Faculty of Medicine, Al-Azhar University, Cairo, Egypt.

\begin{abstract}
Background: Rotator cuff, acute or chronic tendonitis, is affected by diabetes and hypothyroidism. Physiotherapy plays a pivotal role in the outcome and improvement of rotator cuff tendinopathy. This crosssectional study was conducted on forty patients with shoulder pain.

Aim of The Work: to study the impact of different physiotherapy programs in both hypothyroid and diabetic rotator shoulder cuff tendinitis.

Patients and Methods: This is a Prospective cross-sectional study conducted in Egypt during the period from August 2019 till August 2020 .The present work was conducted on forty patients, ages (25-35) with disease duration of two to three years complaining of mechanical and inflammatory shoulder pain.

Results: The mean of range of motion (ROM) among hypothyroid patients was $22.3 \pm 25.69$ at first visit and increased to $77.7 \pm 65.02$, whereas, the mean ROM among diabetic patients was $31.00 \pm 24.153$ at first visit and increased to $101.55 \pm 61.90$. The ROM was of high statistically significant difference from at the first visit and after 3 months (P-value $<0.001)$. The mean pain scale among hypothyroid patients was $5.45 \pm 1.986$ at the first visit and decreased to $2.05 \pm 1.638$, whereas, the mean Pain scale among diabetic patients was $5.20 \pm 1.80$ at the first visit and decreased to $1.80 \pm 1.473$. However, the Pain scale was not of statistically significant difference from at the first visit and after 3 months ( $\mathrm{p}$ value $>0.05$ )

Conclusion: Our results reinforce the value of physiotherapy in improving the symptoms of rotator cuff tendinitis by increasing the ROM, and improving pain and MRI, however, there was no statistical difference between hypothyroid and diabetic patients regarding the age, side of affection, ROM and pain.

Keywords: Physiotherapy; rotator cuff; shoulder tendinitis; diabetes; hypothyroidism.
\end{abstract}

\footnotetext{
Disclosure: The authors have no financial interest to declare in relation to the content of this article. The Article Processing Charge was paid for by the authors.

Authorship: All authors have a substantial contribution to the article.
}

\section{INTRODUCTION}

Either acute or chronic Rotator Cuff (RC) tendinitis are secondary to repeated eccentric environmental forces and predisposing anatomic/mechanical risk factors. These injuries result in focally injured cuff regions which may evolve into partial thickness tears (PTTs) or full thickness tears (FTTs), depending on the type of eccentric forces of a rotator cuff. ${ }^{1}$

However, it is still unclear if Rotator cuff tendonopathy pathogenesis entails a variety of variables such as hereditary predisposition, extrinsic impingement and biomechanical mismatch in mango systems and intricate degeneration from tendon modifications themselves and eventually comorbidity. ${ }^{2}$

Extrinsic factors include acromion form, glenohumeral and disruption, overuse syndrome and multiple demographic factors. Systematic diseases such as diabetes mellites, hypocholesteremia and thyroid. The effects of revolving cuff repair have a direct effect and are significant for the treatment of these patients. ${ }^{3}$

In the production and exacerbation of rotator cuff tendinitis several medical conditions play a potential role. Rotator cuff pathology linked to metabolic syndrome and related diagnoses (such as dyslipidemia, hypertension, hyperglycemia and abdomen obesity). ${ }^{4}$

Several epidemiological researches related to shoulder disorders and diabetes RC pathology. ${ }^{5}$ The specific pathways by which diabetes is associated with rotator cuff tendinitis can be postulated to be non-enzymatic glycosylation and compromised microcirculation at rotator cuff tendons. A major mechanism for tendon degeneration and inflammation was suggested for non-enzymatic glycosylation by collagen with advanced glycationend products (AGEs) creation. AGEs build-up biochemical and mechanical properties after RC tears 
probably modifies the $\mathrm{RC}$ tendon by enhanced crosslinking of intermolecular collagen. ${ }^{6}$

In controlling a multitude of adult metabolic functions, from gene regulation to affecting thermogenesis, cell formation, and mitochondrial processes, the role of thyroid hormones in the production of shoulder tendinopathy is crucial. Tendinopathy may also be the signs in a hypothyroid patient with often good treatment following endocrine disease control. ${ }^{7}$

It is advised to treat symptoms alone by nonoperating methods. Partial or full-thickness rotator cuff tears often develop without symptoms in patients with MRI-evidence. ${ }^{8}$

In order to determine the general degree of rotator cuff pathology, Magnetic Resonance Imaging offers more precise cuff tear data than conventional radiology, including partial-to-full thick tears, size of the tears, place, or withdrawal. ${ }^{9}$

This research was carried out to study the impact of different physiotherapy modalities programs in the form of cryotherapy, ultrasound, trans-cutaneous electeric nerve stimulation (TENS), high power laser therapy and radial extracorporeal shock wave therapy alternatively with strengthening, stretching and range of motion exercise in both hypothyroid and diabetic rotator shoulder cuff tendinitis. Also, to evaluate the clinical and radiological condition before and after using different physiotherapy modalities in both gender in hypothyroid and diabetes rotator shoulder cuff tendinitis patients.

\section{PATIENTS AND METHODS}

This is a Prospective cross-sectional study conducted in Egypt during the period from August 2019 till August 2020.

The present work was conducted on forty patients, ages (25-35) with disease duration of two to three years complaining of mechanical and inflammatory shoulder pain. All patients were divided into two groups:

Group I: included 20 patients with hypothyroidism and shoulder rotator cuff tendinitis.

Group II: included 20 patients who are diabetic with shoulder rotator cuff tendinitis.

Inclusion criteria: included all patients were complaining of hypothyroid disease, diabetes type I or type II, rotator cuff shoulder tendinitis. Patients should only be on pharmacotherapy for controlling diabetes and hypothyroidism

Exclusion criteria: included patients taking any nonsteroidal anti-inflammatory or analgesic medication, with any history of trauma, sports injury, other endocrinal disorders, cardio vascular disorders tuberculosis, Parkinson's disease and cervical disorders.

\section{Methods}

All patient groups were subjected to complete history taking, a thorough clinical examination, and accurate diagnosis of hypothyroidism and diabetes and received full laboratory investigations and radiological assessment of diabetes or hypothyroid shoulder.

\section{A. Clinical assessment of rotator cuff tendonopathy}

Assessment of the severity and quality of pain of shoulder cuff tendinitis;

Clinically the patients are subjected to Visual Analogue Scale (0-10) numeric pain rating scale for determining the severity and quality of pain. ${ }^{(10)}$

Assessment of the range of motion of the shoulder joint;

Also, the range of motion of the shoulder joint is assessed by using goniometry to measure normal abduction, adduction internal and external rotation and also flexion and extension of shoulder joint especially for the shoulder rotator cuff muscle tendons.

B. Laboratory investigations:

A complete thyroid profile for every patient was done including Free T3,Free T4 and TSH serum:

Diagnostic workup for diabetes via laboratory investigation of the fasting blood sugar level, post prandial blood sugar, and the glycosylated hemoglobin (HbA1c) serum levels.

C-Radiological assessment of diabetes or hypothyroid shoulder:

Assessment of the hypothyroid and diabetic shoulder cuff tendinitis

Hypothyroid and diabetic shoulder cuff tendinitis is classified into:

Mild tendinitis is characterized by slight focal rise on the proton density tendon signal and fat $\mathrm{T} 2$ sequences not identical to the fluid suppressed.

Moderate tendinitis is characterized by moderate focal rise on the proton density tendon signal and fat $\mathrm{T} 2$ sequences not identical to the fluid suppressed.

Sever tendinitis is characterized by marked general rise in tendon signals without the frank strength of signals.

Findings of thickening in homogeneous rotator cuff tendons with increase in the signal intensity on all pulse sequence sometimes is associated with calcified tendinitis.

\section{Management plan:}

All patients of the studied groups were examined by a rheumatologist at (0) base line first visit and after three months alternative different physiotherapy modalities associated with physical exercises

The basic line $(0)$ for management is put for all patients, then follow up was offered to all patients' groups:

The plan of physiotherapy program regimens was scheduled in the form of two stages:

The first stage: persist for one and half months using different physiotherapy modalities such as electrical therapy (TENS) cryotherapy, ultrasound with strengthening, stretching and the range of motion exercises; 3 sessions weekly for $30 \mathrm{~min}$. 
The second stage: The second stage consists of another different physiotherapy modalities using high power laser therapy, radial shock wave therapy and also the same strengthening, stretching and range of motion exercise.

Again, the both groups were investigated via clinical laboratory radiological assessment and subjected after three months for different physiotherapy modalities alternatively as a second follow-up visit.

\section{Statistical Analysis:}

The collected data was revised, coded and tabulated using Statistical package for Social Science (IBM Corp. Released 2011. IBM SPSS Statistics for Windows, Version 21.0. Armonk, NY: IBM Corp.). Data were presented and suitable analysis was done according to the type of data obtained for each parameter. The Mean and standard deviation (mean \pm $\mathrm{SD)}$ were used to describe the parametric numerical data, while the median and range were used for the non-parametric numerical data. The frequency and percentage were used to describe the non-numerical data. The Kolmogorov Smirnov test was done to test the normality of data distribution. The significant data was considered to be nonparametric. The deviations from Hardy-Weinberg equilibrium expectations were determined using the chi-squared test. The groups were compared with Student $t$ test. For all these tests, the level of significance (P-value) was adjusted to $<0.05$.

\section{RESULTS}

Our study involved 40 patients, divided into 2 groups, gender and age matched, each group contain 20 middle age patients where the mean of age in hypothyroidism and diabetics groups was 32.35 \pm 8.62 and $29.81 \pm 5.39$ years, respectively. As regard to the side affected, the left shoulder was the most affected side in both groups (55\% vs $65 \%)$. Regarding the affected tendons in groups, I \& II, supraspinatus affects $50 \% \& 60 \%$ of patients, subscapularis teres major $30 \%$ \& $15 \%$ and infraspinatus teres minor $20 \%$ \& $25 \%$ respectively.
Neither the side of affection, shoulder dominance nor the affected tendon showed significant differences between and within groups ( $\mathrm{p}$ value $>0.05$ ) (table 1).

The range of motion (ROM) among hypothyroid and diabetic patients increased from its value at the first visit to about three times after the 3 months' physiotherapy. The mean ROM among hypothyroid patients was $22.3 \pm 25.69$ at first visit and increased to $77.7 \pm 65.02$, whereas, the mean ROM among diabetic patients was $31.00 \pm 24.153$ at first visit and increased to $101.55 \pm 61.90$. The ROM was of high statistically significant difference from at the first visit and after 3 months (P-value < 0.001). However, the ROM was not of statistically significant difference from at the first visit and after 3 months between hypothyroid and diabetic patients ( $\mathrm{p}$ value $>0.05$ ) (table 2 ).

The Pain scale among hypothyroid and diabetic patients decreased from to about half its value at the first visit after the 3 months' physiotherapy. The mean Pain scale among hypothyroid patients was $5.45 \pm 1.986$ at the first visit and decreased to $2.05 \pm 1.638$, whereas, the mean Pain scale among diabetic patients was $5.20 \pm 1.80$ at the first visit and decreased to $1.80 \pm 1.473$. However, the Pain scale was not of statistically significant difference from at the first visit and after 3 months ( $p$ value $>0.05$ ). The Pain scale was of high statistically significant difference from at the first visit and after 3 months (P-value < 0.001) (table 3).

The size of calcification among hypothyroid and diabetic patients was missing in most of our cases. The Size of calcification by MRI was of high statistically significant difference from at the first visit and after 3 months (P-value < 0.001). However, there was no significant difference in the MRI findings in both hypothyroid or diabetic patients at baseline visit and after 3 months' physiotherapy (table 4).

\begin{tabular}{|c|c|c|c|}
\hline & Hypothyroidism group I $(n=20)$ & $\begin{array}{l}\text { Diabetic } \\
\text { group II }(n=20)\end{array}$ & $P$ value \\
\hline Age (year) Mean +SD & $32.35 \pm 8.62$ & $29.81 \pm 5.39$ & 0.318 \\
\hline Sex & $\begin{array}{l}\text { Female } 12(60 \%) \\
\text { Male } 8(40 \%)\end{array}$ & $\begin{array}{l}\text { Female12(60\%) } \\
\text { Male } 8(40 \%)\end{array}$ & 0.277 \\
\hline $\begin{array}{l}\text { Mean disease duration } \\
\text { in months+SD }\end{array}$ & $19.7+6.14$ months & $28.2+5.21$ months & 0.318 \\
\hline Laboratory results & TSH Miu/L (3.94_0.47) & FBS mg/DL $(87 \pm 9.77)$ & \\
\hline mean+SD & $\begin{array}{l}\text { FT3 pg/DL }(339.55 \pm 50.35) \\
\text { FT4 ng/DL }(1.25+0.39)\end{array}$ & $\begin{array}{l}\text { PPBS mg/DL }(179 \pm 14.09) \\
\text { HbA1c\% }(6.76+0.37)\end{array}$ & \\
\hline Side affected: & & & 0.157 \\
\hline - $\quad$ Right & $9(45 \%)$ & 7 (35\%) & \\
\hline - Left & $11(55 \%)$ & $13(65 \%)$ & \\
\hline Tendon affected: & & & 0.526 \\
\hline -Supraspinatus & $10(50 \%)$ & $12(60 \%)$ & \\
\hline -Subscapularis & $6(30 \%)$ & $3(15 \%)$ & \\
\hline -Infraspinatus & $4(20 \%)$ & $5(25 \%)$ & \\
\hline
\end{tabular}

TSH (thyroid stimulating hormone), FT3 (Free T3), FT4 (Free T4), FBS (Fasting blood sugar), PPBS (Postprandial blood sugar), HbA1c (Glycosylated hemoglobin)

Table 1: Descriptive data of both patient groups as regards age, sex, disease duration, laboratory investigationa, and clinical evaluation 


\begin{tabular}{|c|c|c|c|}
\hline \multirow[t]{2}{*}{ ROM } & $\begin{array}{l}\text { Hypothyroidism group I } \\
(\mathbf{n = 2 0 )}\end{array}$ & Diabetic group II $(n=20)$ & \multirow[t]{2}{*}{$P$ value } \\
\hline & Mean +SD & Mean +SD & \\
\hline Baseline & $22.30+25.69$ & $31.0+24.15$ & 0.277 \\
\hline After 3 months & $77.70+65.02$ & $101.55+61.90$ & \multirow{2}{*}{0.242} \\
\hline P\# value & $\mathrm{P}<0.001 * *$ & $<0.001 * *$ & \\
\hline \multicolumn{4}{|c|}{$\begin{array}{l}\text { \# Comparison between baseline and after } 3 \text { months } * * \text { high significant } \\
\text { Range of motion is measured in degrees } \\
\text { Table 2: The ROM at baseline visit and after } 3 \text { months' alternative physiotherapy among hypothyroid and diabetic } \\
\text { patients }\end{array}$} \\
\hline \multirow[t]{2}{*}{ Pain scale } & $\begin{array}{l}\text { Hypothyroidism group I } \\
(\mathrm{n}=20)\end{array}$ & $\begin{array}{l}\text { Diabetic } \\
\text { group II }(\mathrm{n}=20)\end{array}$ & \multirow[t]{2}{*}{ P value } \\
\hline & Mean +SD & Mean +SD & \\
\hline Baseline & $5.45+1.98$ & $5.20+1.93$ & 0.624 \\
\hline After 3 months & $2.05+1.63$ & $1.80+1.47$ & 0.138 \\
\hline P\# value & $\mathrm{P}<0.001 * *$ & $\mathrm{P}<0.001 * *$ & \\
\hline \multicolumn{4}{|c|}{$\begin{array}{l}\text { \# comparison between baseline and after } 3 \text { months } * * \text { high significant } \\
\text { Table 3: The Pain scale at baseline visit and after } 3 \text { months' alternative physiotherapy among hypothyroid and } \\
\text { diabetic patients }\end{array}$} \\
\hline \multirow[t]{2}{*}{ Size of calcification by MRI } & $\begin{array}{l}\text { Hypothyroidism group I } \\
(\mathbf{n = 2 0 )}\end{array}$ & $\begin{array}{l}\text { Diabetic } \\
\text { Group II }(n=20)\end{array}$ & \multirow[t]{2}{*}{ P value } \\
\hline & Mean +SD & Mean +SD & \\
\hline Baseline & $1.85+0.93$ & $1.50+0.68$ & 0.273 \\
\hline After 3 months & $0.65+0.67$ & $0.60+0.681$ & 0.541 \\
\hline P\# value & $\mathrm{P}<0.001 * *$ & $\mathrm{P}<0.001 * *$ & \\
\hline
\end{tabular}

\# Comparison between baseline and after 3 months ** high significant

Size of calcification is measured in $\mathrm{mm}$

Table 4: The MRI at baseline visit and after 3 months' alternative physiotherapy among hypothyroid and diabetic patients
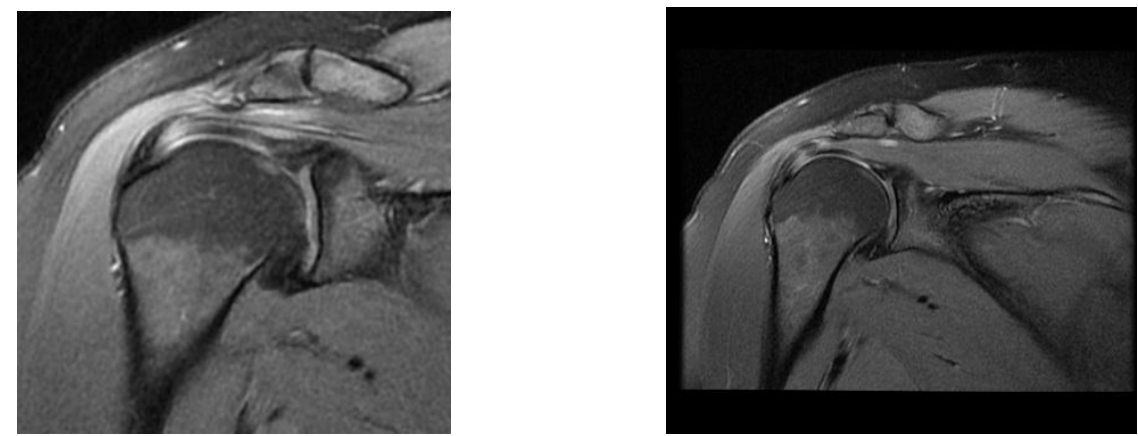

Fig.1: Coronal Proton Density fat saturation supraspinatus tendonopathy. (decreased supraspinatus tendon signal after physiotherapy). 


\section{DISCUSSION}

Physiotherapy has an important role in the effectiveness of rotator cuff surgery, but also varies greatly from therapists to orthopedic surgeons. Thus, both tendinopathies and eventual RC repair are treated based on the impairment pathways involved in genesis of tendon injury. ${ }^{11)}$

In our study, we had 40 patients, divided into 20 with hypothyroidism and rotator cuff tendonopathy and the other 20 were diabetic with rotator cuff tendonopathy. rotator cuff tendonopathy in our study was not due to traumatic injury, but due to systematic injury either hypothyroidism or diabetes, both groups were age and gender matched. There was no significant difference between our study subjects as regard to age. Our patients had affection more on the left shoulder and the supraspinatus which is involved in abduction Neither the side of affection, the shoulder dominance nor the affected tendon showed significant differences between and within groups, this was supported by the results of other studies, which stated that there were no systematic differences between individuals with and without symptoms in their dominant shoulder. ${ }^{12}$

The affection of the supraspinatus more in the rotator cuff tendonopathy is supported in literature, being the most commonly affected, which is explained by understanding the shoulder joint anatomy as a ball and socket joint; where the rotator cuff consists of four scapula-born muscles inserted on the superior humeral head to enhance flexibility. ${ }^{13}$

The range of motion and pain score among hypothyroid and diabetic patients increased from its value at the first visit to about three times after the 3 months' physiotherapy. However, the range of motion was not of statistically significant difference from at the first visit and after 3 months between hypothyroid and diabetic patients. A related research found that physiotherapy enhanced pain/function values and increased range of motion. ${ }^{14}$

Physiotherapy has a positive influence on the health effects of rotator cuff tendonopathy patients, and the results of our study are consistent with previous studies. Kuhn et al. recorded that about 6 weeks of physiotherapy contributed to major pain/function and shoulder range of motion changes. ${ }^{15}$

Enhancements in pain and function experienced by patients are promising in this research because the existing recommendations on clinical practice recommend physiotherapy treatments as the first way to treat rotator cuff tendonopathy. In fact, physiotherapy increases typically exceeded the minimal clinically important difference (MCID) of $10^{\circ}$ to $15^{\circ}$ as reported by Muir et al, the rise in VAS score of approximately 30 points exceeded the MCID of 11.7 and the declining of 2.1 points for visual analogue scale pain exceeded the MCID of 1.4 as previously reported. ${ }^{16}$

The MRI findings in both hypothyroid or diabetic patients at baseline visit and after 3 months physiotherapy showed no significant difference. Similar studies have shown that the discrepancy between MRI and its sensitivity and specificity is not significant. ${ }^{17}$

In our study, the correlation of the endocrinal disorders in the development of rotator cuff tendinopathy was not widely studied as our sample size was equally selected. However, there is an association between thyroid hormones and tendinopathy. Oliva et al. reported a greater prevalence of thyroid disease in women, regardless of age. In the 60-80 years old women the incidence was greatest (women:63\% vs. men:23\%), demonstrating the role of thyroid hormones in the modification and increase of age-related or nontraumatic RC tearing. ${ }^{18}$

\section{Strengths and limitations:}

One of the main strengths in our study is that it is one of the very limited number of reports which analyzed and demonstrated potential changes in non-traumatic rotator cuff tear by the thyroid hormones and diabetes. Also, our study involved only patients with confirmed rotator cuff tendinopathy due to hypothyroidism or diabetes only excluding patients with trauma history, co-morbidities.

Limitations in our study are the small sample size, and the cross-sectional nature limit the chances for the generalization of our results. One of the problems of a cross-section study is the dropout of affected cases, as we faced in the follow-up of the cases to assess the level of calcification.

\section{CONCLUSION}

Our results reinforce the value of physiotherapy in improving the symptoms of rotator cuff tendinitis by increasing the range of motion, and improving pain and MRI, however, there was no statistical difference between hypothyroid and diabetic patients regarding the age, side of affection, ROM and pain.

\section{REFERENCES}

1. Farfaras S, Sernert N, Rostgard Christensen L, Hallström EK, Kartus JT. Subacromial decompression yields a better clinical outcome than therapy alone: a prospective randomized study of patients with a minimum 10-year follow-up. The American journal of sports medicine. 2018 May;46(6):1397-407.

2. Via AG, De Cupis M, Spoliti M, Oliva F. Clinical and biological aspects of rotator cuff tears. Muscles, ligaments and tendons journal. 2013 Apr;3(2):70.

3. Lee S, Gumucio J, Mendias C, Bedi A. What is the role of systemic conditions and options for manipulation of bone formation and bone resorption in rotator cuff tendon healing and repair?. Techniques in shoulder \& elbow surgery. 2017 Sep;18(3):113.

4. Gumina S, Candela V, Passaretti D, Latino G, Venditto T, Mariani L, Santilli V. The association between body fat and rotator cuff tear: the influence 
on rotator cuff tear sizes. Journal of shoulder and elbow surgery. 2014 Nov 1;23(11):1669-74.

5. Ranger TA, Wong AM, Cook JL, Gaida JE. Is there an association between tendinopathy and diabetes mellitus? A systematic review with meta-analysis. British journal of sports medicine. 2016 Aug 1;50(16):982-9.

6. Gumucio JP, Korn MA, Saripalli AL, Flood MD, Phan AC, Roche SM, et al. Aging-associated exacerbation in fatty degeneration and infiltration after rotator cuff tear. Journal of shoulder and elbow surgery. 2014 Jan 1;23(1):99-108.

7. Pantazis K, Roupas ND, Panagopoulos A Theodoraki S, Tsintoni A, Kyriazopoulou V. Spontaneous rupture of the long head of the biceps tendon in a woman with hypothyroidism: a case report. Journal of medical case reports. 2016 Dec;10(1):1-4.

8. Tashjian RZ. AAOS clinical practice guideline: optimizing the management of rotator cuff problems. JAAOS-Journal of the American Academy of Orthopaedic Surgeons. 2011 Jun 1;19(6):380-3.

9. Umer M, Qadir I, Azam M. Subacromial impingement syndrome. Orthopedic reviews. 2012 May $9 ; 4(2)$

10. D. Gould, D Kelly, L Goldstone, J Gammon. Visual Analogue Scale (VAS). Journal of Clinical Nursing 2001; 10:697-706.

11. Seitz AL, McClure PW, Finucane S, Boardman III ND, Michener LA. Mechanisms of rotator cuff tendinopathy: intrinsic, extrinsic, or both?. Clinical biomechanics. 2011 Jan 1;26(1):1-12.

12. Christiansen DH, Michener LA, and Roy JS Influence of dominant- as compared with nondominant-side symptoms on Disabilities of the Arm,
Shoulder and Hand and Western Ontario Rotator Cuff scores in patients with rotator cuff tendinopathy. J Shoulder Elbow Surg.2018;27(6):1112-6.

13. Spargoli G. Supraspinatus tendon pathomechanics: A current concept review. International journal of sports physical therapy. 2018;13(6), 1083-94.

14. Baumer TG, Chan D, Mende V, Dischler J, Zauel R, van Holsbeeck M, Siegal DS, Divine G, Moutzouros V, Bey MJ. Effects of rotator cuff pathology and physical therapy on in vivo shoulder motion and clinical outcomes in patients with a symptomatic full-thickness rotator cuff tear. Orthopaedic journal of sports medicine. $2016 \quad$ Sep 22;4(9):2325967116666506.

15. Kuhn JE, Dunn WR, Sanders R, An Q, Baumgarten KM, Bishop JY, Brophy RH, Carey JL, Holloway BG, Jones GL, Ma CB. Effectiveness of physical therapy in treating atraumatic full-thickness rotator cuff tears: a multicenter prospective cohort study. Journal of shoulder and elbow surgery. 2013 Oct 1;22(10):1371-9.

16. Muir SW, Corea CL, Beaupre L. Evaluating change in clinical status: reliability and measures of agreement for the assessment of glenohumeral range of motion. North American journal of sports physical therapy: NAJSPT. 2010 Sep;5(3):98.

17. Factor D, Dale B. Current concepts of rotator cuff tendinopathy. International journal of sports physical therapy. 2014 Apr;9(2):274.

18. Oliva F, Piccirilli E, Bossa M, Via AG, Colombo A, Chillemi C, Gasparre G, Pellicciari L, Franceschetti E, Rugiero C, Scialdoni A. IS Mu. LT-Rotator cuff tears guidelines. Muscles, ligaments and tendons journal. 2015 Oct;5(4):227. 